pathogenic bacteria. To lower the chance that resistance will develop, the patients will receive a cocktail of more than a dozen phages that enter bacterial cells in different ways. If the phage treatment fails, patients will then receive standard antibiotics.

Although governments are starting to pay attention to phage therapy, pharmaceutical companies remain reluctant to get on board, Young says. Because phage therapy is nearly a century old, it would be difficult for a company to claim a treatment as intellectual property, and therefore recoup its costs. Young says it is likely that a 2013 ruling by the US Supreme Court against the patenting of natural genes would also apply to phages isolated from nature. Jérôme Gabard, chief executive of Pherecydes, says that the company is banking on hopes that developing and characterizing precise combinations of natural phages to target particular bacteria will be patentable.

An engineered phage could, in theory, be patented. At the ASM meeting last month, researchers led by synthetic biologist Timothy $\mathrm{Lu}$ at the Massachusetts Institute of Technology in Cambridge presented work on a phage engineered to use a DNA-editing system called CRISPR to kill only antibioticresistant bacteria. The phage injects the bacterium with DNA, which the microbe transcribes into RNA. If part of the bacterium's antibiotic-resistance gene matches that RNA sequence, an enzyme called Cas 9 cuts up the cell's DNA, killing it.

In initial trials, the researchers found that their phage could kill more than $99 \%$ of the $E$. coli cells that contained specific antibiotic-resistance gene sequences, whereas it left susceptible cells alone. Giving the phage to waxworm larvae infected with resistant E. coli increased the worms' chance of survival. The researchers are now starting to test the system in mice (human trials are a long way off).

Gabard does not expect that phage therapy will ever replace antibiotics. But he says that he can envisage regulatory agencies approving it for patients in whom drug treatments have failed. And some people with antibiotic-resistant infections are taking matters into their own hands. Kutateladze says that an increasing number of EU patients are travelling to Georgia for phage treatment. She adds that doctors in some EU countries send patients' samples to the Eliava Institute, which then sends back a phage cocktail specific to the bacterium causing the infection. "When there's no hope, you'll do anything," Schmidt says.

Meanwhile, researchers are watching the Phagoburn study with interest, hoping that it will lay the groundwork for moving the technology into the clinic. "We just need one really great success for the field to really open up," says Lu.

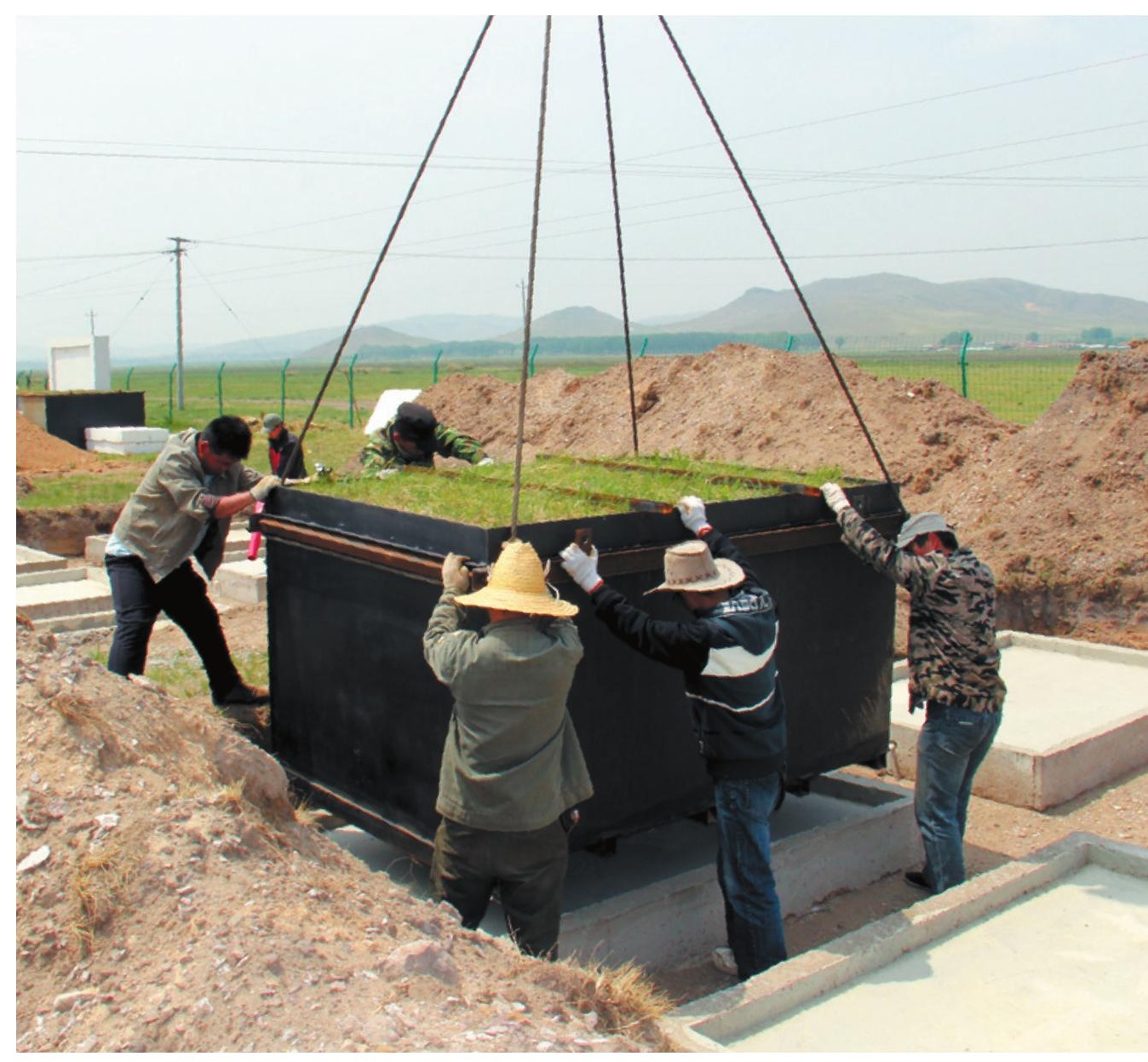

Sections of Mongolian grassland will undergo climate-manipulation analysis at the Duolun research centre.

GLOBAL WARMING

\title{
Land models put to climate test
}

\section{Study under way on Mongolian steppes aims to improve knowledge of warming effects on vegetation.}

\section{BY JANE QIU}

$\mathrm{S}$ hiqiang Wan remembers his first experience of a major sandstorm more than a decade ago in Inner Mongolia. "It was like sands being dumped on me by a gigantic dustbin," he says. "I couldn't see anything just a few metres away." Decades of overgrazing were turning the region into desert.

Grassland is now developing there again after strict grazing limits were imposed on the autonomous region by China in 2000 . But Wan, an ecologist at Henan University in Kaifeng, worries that another, more challenging, menace will eat away at vegetation there and elsewhere: climate change. And if grasslands wither on a global scale, "it would not only cause widespread desertification, but accelerate climate warming by increasing carbon dioxide levels in the air", he says.

Yet scientists know little about the effects of climate change on land ecosystems, or how they will affect atmospheric $\mathrm{CO}_{2}$.

Wan and his colleagues have an ambitious plan for filling that information vacuum. In a US $\$ 260,000$ operation, they have cut 54 6 -tonne chunks of soil -2.2 metres by 1.5 metres, by 1.2 metres deep - from three types of grassland in the Mongolian Plateau, and are now growing them at the 
Duolun Ecological Research Station in the region. Later this month, the team will start a decade-long experiment to test how artificially induced warming and varying amounts of rainfall affect vegetation growth, water, nutrients and plant composition. More crucially, it will investigate the underlying mechanisms.

The importance of the experiment "goes beyond the Mongolian steppes", says Alan Knapp, an ecologist at Colorado State University in Fort Collins. "Grasslands across broad temperature and precipitation gradients can respond quite differently to climate change - in some cases, as differently as between a grassland and a forest."

Models that simulate how terrestrial ecosystems respond to climate change and affect atmospheric $\mathrm{CO}_{2}$ levels fail to capture these nuances, Knapp told a meeting last month in Beijing. The meeting was funded by the US National Science Foundation with the aim of fostering closer ties between experimentalists and modellers. The models used assume that a given type of vegetation will behave in the same way, regardless of the local climate. "Historically, ecologists tend to work in their backyard and assume everywhere else is the same," Knapp says.

Not only that, but studies conducted at different locations are often not comparable because different teams address different questions, and their experimental protocols also vary. For this and other reasons, few data from the hundreds of manipulation experiments conducted worldwide - at a cost of billions of dollars - have been incorporated into the models, says Yiqi Luo, a climate modeller at the University of Oklahoma in Norman.

Until recently, "there has been limited crossover between experimentalists and modellers", says Jeff Dukes, an ecologist at Purdue University in West Lafayette, Indiana. Typically, "we would turn to modellers years after an experiment has begun and then realize things that we should have measured are not measured", adds Richard Norby, an ecologist at Oak Ridge National Laboratory in Tennessee. "We would have made a lot faster progress if the two communities had worked closely together from the very beginning."

The key to success lies partly in collecting the right data for the model from the start. Wan's study will be among the first to do this, and is one of a growing number of

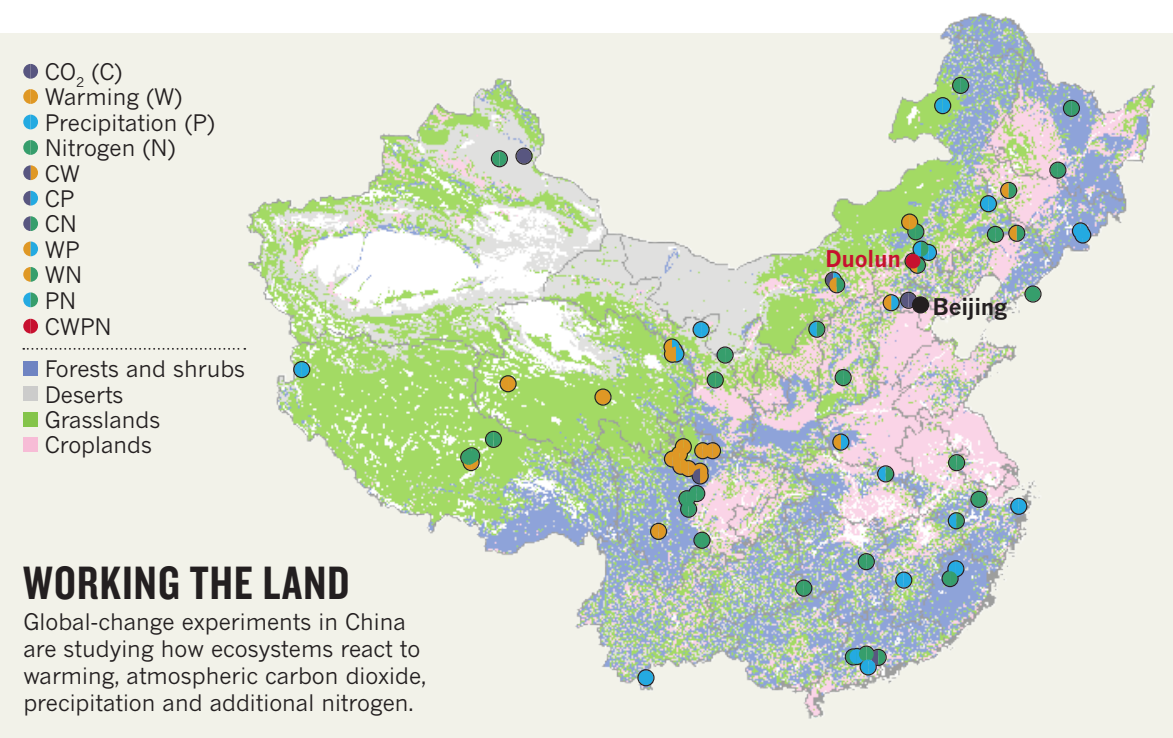

such 'global-change' experiments for land ecosystems (see 'Working the land'). It will measure a range of factors that are needed to drive models, such as soil carbon content and nutrient level, plant biomass and productivity, and meteorological parameters. Results from the study could, for example, be the first step to making comparisons across a rainfall gradient, and so improve land models, Luo says.

Wan's initiative will be welcome. The performance of land models "is rather poor at the moment", says Philippe Ciais, a climate modeller at the National Centre for Scientific Research in Paris. For instance, their predictions of $\mathrm{CO}_{2}$

"Grasslands across broad temperature and precipitation gradients can respond quite differently to climate change." release from land ecosystems in response to changes in atmospheric $\mathrm{CO}_{2}$, temperature and other climate variables diverge wildly (V. K. Arora et al. J. Clim. 26, 5289-5314; 2013). Land models "are the weakest link in our projection of future climate change", Ciais adds.

To understand why the models differ so much, the US Department of Energy is funding a project, led by Norby, to compare experimental data and land models. "Initially, we wanted to see which models fit the data best," says Norby. "But we soon realized that this isn't the right approach because models can give the right answer for the wrong reason."

The team found, for instance, that most models are flawed in their basic assumptions about how plants use nitrogen, but can still reproduce some of the effects seen in global-change experiments because errors in opposite directions cancel each other out (S. Zaehle et al. New Phytol. http://dx.doi.org/10.1111/nph.12697; 2014). "This means that they are not going to be very powerful for predicting the future," says Norby.

At the Beijing meeting, researchers identified other weaknesses. The models are poor at capturing how vegetation composition responds to climate change - a crucial factor for predicting changes in carbon storage in the long term. This is partly because the models tend to be based on the physiology of single plants and partly because they take scant account of plant diversity.

To improve land models, researchers at the meeting plan to launch long-term initiatives to probe how ecosystems worldwide respond to climate change and to standardize experimental designs and methods so that the results can be compared.

The ecologists are also calling for a common repository for data from global-change experiments that can be accessed by modellers similar to existing databases for atmospheric and oceanic observations.

"There is a long way to go," says Luo. "To connect experimentalists and modellers is the key. The bridge has just started being built." -

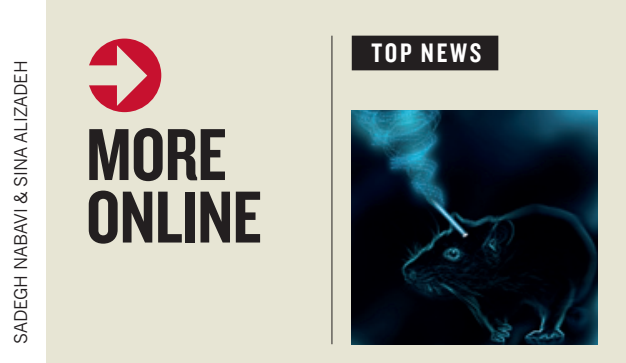

Optogenetics provides direct evidence for memory model go.nature. com/zspprs

\section{MORE NEWS}

- Publication record predicts who will become a principal investigator go.nature.com/ledkav

- Lianas protect trees from lightning go.nature.com/rchaaz

- Stellar winds make planets uninhabitable go.nature.com/i7qtkp

\section{NATURE PODCAST}

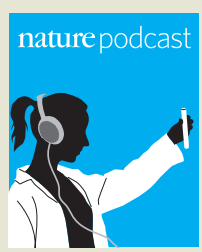

Malnutrition and microbiota; the basis of memory; and China moves mountains to build cities nature.com/ nature/podcast 